\title{
Disrupted Retinotopic Maps in Amblyopia
}

\author{
Behzad Mansouri, ${ }^{1}$ Bruce C. Hansen, ${ }^{1,2}$ and Robert F. Hess ${ }^{1}$
}

Purpose. The amblyopic visual system exhibits both positional inaccuracy (uncertainty) and systematic biases (distortion). The fidelity of the retinotopic representation of the visual field driven by the amblyopic eye was studied for each of these aspects of position coding by using a dichoptic position-matching task.

MethoD. Fifteen patients with amblyopia and five normal subjects were tested. The stimuli were luminance-defined Gaussian blobs that were presented within a circle of $15^{\circ}$ diameter. Each Gaussian blob was seen only by the amblyopic eye. Moving a mouse marker seen only by the fellow fixing eye (perceptual matching measure), each subject had to localize the position of previously presented targets.

REsults. The results confirm previous findings that there is significant distortion in the maps of the central visual field in amblyopic subjects. However, the uncertainty measure did not correlate with the measured distortion in amblyopic maps nor with the visual acuity. Also, regional analysis of the data showed that the distortion occurred heterogeneously in different parts of the visual field and had no relationship to the associated strabismus.

Concuusions. The underlying explanations for these three visual deficits-inaccuracy, distortion, and acuity loss-may be different. (Invest Ophthalmol Vis Sci. 2009;50:3218-3225) DOI:10.1167/iovs.08-2914

$\mathrm{A}$ mblyopia is a developmental disorder that usually occurs in one eye and is responsible for irreversible monocular impairment in adults. It involves several visual deficits, with acuity and contrast sensitivity being the most studied. ${ }^{1,2}$ It also involves positional inaccuracy ${ }^{3}$ and positional distortion, ${ }^{4}$ important deficits that have received less attention.

Humans with strabismic amblyopia, though not those with nonstrabismic anisometropic amblyopia, display increased uncertainty for positional tasks with their amblyopic eyes that do not follow as a simple consequence of associated deficits in contrast sensitivity. ${ }^{5}$ Furthermore, this deficit, unlike their contrast sensitivity deficit, is scale-invariant. Positional uncertainty is elevated to a similar extent for large objects of low spatial frequency as it is for small objects of high spatial frequency. ${ }^{5}$ Such a deficit would be expected to produce substantial perceptual consequences. ${ }^{6}$ Besides an elevated uncertainty for position, subjects with strabismic amblyopia display fixed spatial biases (i.e., distortions) for positional judgements ${ }^{4,5,7-17}$ and perceive spatial distortions in general. ${ }^{18}$

From the ${ }^{1}$ McGill Vision Research Unit, Ophthalmology Department, McGill University, Montreal, Quebec, Canada; and the ${ }^{2}$ Department of Psychology, Colgate University, Hamilton, New York.

Supported by the Canadian Institute of Health Research (CIHR) Grant MT108-18 (RFH).

Submitted for publication September 19, 2008; revised November 12 and 28, 2008, and January 12 and 30, 2009; accepted May 14, 2009. Disclosure: B. Mansouri, None; B.C. Hansen, None; R.F. Hess, None

The publication costs of this article were defrayed in part by page charge payment. This article must therefore be marked "advertisement" in accordance with 18 U.S.C. $\$ 1734$ solely to indicate this fact.

Corresponding author: Robert F. Hess, 687 Pine Avenue, W. (H414), Montreal, Quebec H3A 1A1, Canada; robert.hess@mcgill.ca.
Animal models of amblyopia due to lid suture or strabismus also show a profound loss of positional accuracy. Even though visual acuity recovers when the animal is subjected to normal binocular stimulation ${ }^{19}$ or when the fellow eye is reverse occluded, the positional deficit remains. ${ }^{20}$ The positional deficit in deprived animals is substantial, there usually being greater than an order of magnitude between the accuracy of the amblyopic and fellow eyes, and, like the human equivalent, it exhibits the property of spatial scale invariance. Although it is true that explanations couched in terms of undersampling ${ }^{21}$ or uncalibrated disarray ${ }^{22}$ could equally account for the positional uncertainty, the explanation for the spatial distortion is more easily modeled by hypothesizing a spatial disarray. ${ }^{6}$ The fact that such comparable positional deficits occur in humans with amblyopia and in animals deprived of vision during the critical period of visual development suggests that our ability to encode the relative position of objects undergoes development and can be easily disrupted with profound perceptual consequences.

Several important questions concerning the positional deficit in amblyopia are yet to be adequately answered. For example: What is the relationship between the deficits for uncertainty, distortion, and acuity? What is the regional distribution of these deficits within the central $30^{\circ}$ visual field, and do they bear any simple relationship to the direction of the associated strabismus?

Regarding the first question, there is considerable disagreement. In several studies, ${ }^{4,7,23,24}$ investigators have argued that distortions, uncertainty, and acuity loss are correlated, at least in strabismic amblyopia. Other investigators ${ }^{9,12,17}$ have also argued for a correlation between the spatial distortions/spatial uncertainty and acuity loss in strabismic amblyopia. On the other hand, some $e^{5,16,25}$ have found no significant correlation between either spatial measure (i.e., distortions or uncertainty) and the loss of contrast sensitivity. There is also no clear consensus concerning the second question relating to the regional distribution of the positional loss. The distribution of the deficit for distortion was initially reported to be confined to the central field $\left(2.5^{\circ} \text { radius }\right)^{9}$; however, later evidence using a different task showed that it was greater in a region beyond a $2.5^{\circ}$ radius (but within a $20^{\circ}$ radius)..$^{9,12}$ Other work ${ }^{16}$ suggests that the distortion is greater beyond $5^{\circ}$ eccentricity but that the distribution of the elevated uncertainty depends on the spatial scale used to measure it.

Our purpose was to examine each of these currently unresolved issues by comparing spatial distortion and spatial uncertainty across the central visual field in a group of subjects mainly having strabismic amblyopia (one with deprivation amblyopia and one with anisometropic amblyopia), to ascertain their relationship to the acuity loss as well as their regional distribution.

\section{Methods}

\section{Apparatus}

All stimuli were generated by computer (Intel Pentium IV, 2.4-GHz processor equipped with 1-Gb RAM; Intel, Mountain View, CA). Stimuli were displayed by using a linearized look-up table (22-in. NuVision 21 MX-SL CRT driven by a VSG2/5 graphics card; Cambridge Research Systems, Cambridge, UK) with 15-bit gray-scale resolution. Maximum 
Table 1. Clinical Details of Amblyopic Subjects

\begin{tabular}{|c|c|c|c|c|c|c|}
\hline Subj. & Age & Type & Refraction & Acuity & Strab & History, Stereo (Randot Test) \\
\hline ED & 43 & LE strab & $\begin{array}{l}\mathrm{R}:+0.75 \text { DS } \\
\mathrm{L}:+0.75 \mathrm{DS}\end{array}$ & $\begin{array}{l}20 / 16 \\
20 / 63\end{array}$ & $\begin{array}{l}\text { ET } \\
5 \text { PD }\end{array}$ & Detected at age 6 years, patching for 1 year, stereo 40 seconds \\
\hline $\mathrm{EF}$ & 56 & LE strab & $\begin{array}{l}\mathrm{R}:+2.00+1.00 \times 180^{\circ} \\
\mathrm{L}:+2.00+1.00 \times 130^{\circ}\end{array}$ & $\begin{array}{l}20 / 32 \\
20 / 250\end{array}$ & $\begin{array}{l}\text { ET } \\
10.5 \text { PD }\end{array}$ & $\begin{array}{l}\text { Detected at } 6 \text { years, patching for } 1 \text { to } 2 \text { years, no surgery, no } \\
\text { stereo }\end{array}$ \\
\hline GN & 30 & RE mixed & $\begin{array}{l}\mathrm{R}:+5.00-2.00 \times 120^{\circ} \\
\mathrm{L}:+3.00-1.00 \times 75^{\circ}\end{array}$ & $\begin{array}{l}20 / 70 \\
20 / 20\end{array}$ & $\begin{array}{l}\text { ET } \\
14 \text { PD }\end{array}$ & $\begin{array}{l}\text { Detected at } 5 \text { years, patching } 3 \text { months, no glasses, strabismus } \\
\text { surgery RE } \times 2 \text { age } 10-12 \text { years, no stereo }\end{array}$ \\
\hline $\mathrm{PH}$ & 33 & LE strab & $\begin{array}{l}\mathrm{R}:-1.00+0.50 \times 10^{\circ} \\
\mathrm{L}: \text { plano }\end{array}$ & $\begin{array}{l}20 / 25 \\
20 / 63\end{array}$ & $\begin{array}{l}\text { ET } \\
9 \mathrm{PD}\end{array}$ & $\begin{array}{l}\text { Detected at } 4 \text { years, patching for } 6 \text { months; surgery age } 5 \\
\text { years, no stereo }\end{array}$ \\
\hline LS & 22 & BE depr & $\begin{array}{l}\mathrm{R}:-2.00+0.50 \times 90^{\circ} \\
\mathrm{L}:+0.50 \mathrm{DS}\end{array}$ & $\begin{array}{l}20 / 20 \\
20 / 125\end{array}$ & Ortho & $\begin{array}{l}\text { Detected at } 5 \text { years, left denser than right bilateral cataract } \\
\text { surgery ages } 5 \text { (RE), } 6 \text { (LE) years; patching (RE) } 4 \text { months at } \\
8 \text { years, no stereo }\end{array}$ \\
\hline MA & 22 & LE aniso & $\begin{array}{l}\mathrm{R}:-0.25 \mathrm{DS} \\
\mathrm{L}:+3.50-0.50 \times 180^{\circ}\end{array}$ & $\begin{array}{l}20 / 15 \\
20 / 200\end{array}$ & Ortho & $\begin{array}{l}\text { Detected at } 3 \text { years, patching for } 4 \text { years, and glasses for } 8 \\
\text { years, no stereo }\end{array}$ \\
\hline MB & 50 & RE strab & $\begin{array}{l}\text { R: }-1.00 \mathrm{DS} \\
\mathrm{L}:+0.50 \mathrm{DS}\end{array}$ & $\begin{array}{l}20 / 32 \\
20 / 80\end{array}$ & $\begin{array}{l}\text { ET } \\
5 \text { PD }\end{array}$ & No surgery, first glasses at 32 years, no stereo \\
\hline MG & 30 & RE strab & $\begin{array}{l}\mathrm{R}:+1.50 \mathrm{DS} \\
\mathrm{L}:+1.50 \mathrm{DS}\end{array}$ & $\begin{array}{l}20 / 100 \\
20 / 15\end{array}$ & $\begin{array}{l}\text { ET } \\
2 \text { PD }\end{array}$ & Detected at 4 years, patching for 6 months, no surgery, no \\
\hline ML & 20 & RE mixed & $\begin{array}{l}\mathrm{R}:+1.0-0.75 \times 90^{\circ} \\
\mathrm{L}:-3.25 \mathrm{DS}\end{array}$ & $\begin{array}{l}20 / 80 \\
20 / 25\end{array}$ & $\begin{array}{l}\text { ET } \\
10.5 \text { PD }\end{array}$ & Detected at 5 years, patching for 2 years, no stereo \\
\hline $\mathrm{OA}$ & 21 & RE mixed & $\begin{array}{l}\mathrm{R}:-4.50-5.00 \times 30^{\circ} \\
\mathrm{L}:-1.75 /-1.75 \times 150^{\circ}\end{array}$ & $\begin{array}{l}20 / 80 \\
20 / 20 \\
20 / 32\end{array}$ & $\begin{array}{l}\text { ET } \\
9 \mathrm{PD}\end{array}$ & Detected at 3 years, patching at 3 years, no surgery, no stereo \\
\hline RA & 49 & LE strab & $\begin{array}{l}\mathrm{R}:+3.50 \mathrm{DS} \\
\mathrm{L}:+4.75-0.75 \times 45^{\circ}\end{array}$ & $\begin{array}{l}20 / 15 \\
20 / 40\end{array}$ & $\begin{array}{l}\mathrm{XT} \\
4 \mathrm{PD}\end{array}$ & $\begin{array}{l}\text { Detected at } 6 \text { years, glasses since } 6 \text { years, no other therapy, } \\
\text { stereo } 400 \text { seconds }\end{array}$ \\
\hline VD & 23 & LE mixed & $\begin{array}{l}\mathrm{R}:+0.25 \mathrm{DS} \\
\mathrm{L}:+2.75-1.25 \times 175^{\circ}\end{array}$ & $\begin{array}{l}20 / 20 \\
20 / 40\end{array}$ & $\begin{array}{l}\text { ET } \\
4 \mathrm{PD}\end{array}$ & $\begin{array}{l}\text { Detected at } 5-6 \text { years, patching for } 6 \text { months, no surgery, } \\
\text { stereo } 50 \text { seconds }\end{array}$ \\
\hline $\mathrm{VE}$ & 69 & LE mixed & $\begin{array}{l}\mathrm{R}:+4.5-5.00 \times 30^{\circ} \\
\mathrm{L}:-1.75-1.75 \times 150^{\circ}\end{array}$ & $\begin{array}{l}20 / 80 \\
20 / 25\end{array}$ & $\begin{array}{l}\text { ET } \\
9 \text { PD }\end{array}$ & Detected at 10 years, no treatment, no stereo \\
\hline XL & 31 & LE mixed & $\begin{array}{l}\mathrm{R}:-2.50 \mathrm{D} \\
\mathrm{L}:-2.75 \mathrm{D}\end{array}$ & $\begin{array}{l}20 / 20 \\
20 / 400\end{array}$ & $\begin{array}{l}\text { ET } \\
27 \text { PD }\end{array}$ & Detected at 13 years, no treatment, no stereo \\
\hline YC & 31 & LE strab & $\begin{array}{l}\mathrm{R}:+2.00 \mathrm{D} \\
\mathrm{L}:+2.00 \mathrm{D}\end{array}$ & $\begin{array}{l}20 / 15 \\
20 / 40\end{array}$ & $\begin{array}{l}\text { ET } \\
18 \mathrm{PD}\end{array}$ & $\begin{array}{l}\text { Detected at } 2 \text { years, patching for } 4 \text { years, glasses for } 16 \text { years, } \\
\text { no stereo }\end{array}$ \\
\hline
\end{tabular}

strab, strabismic amblyopia; DS, ; ET, : PD, ; depr, deprivation amblyopia.

luminance was $80 \mathrm{~cd} / \mathrm{m}^{-2}$, the frame rate was $120 \mathrm{~Hz}$, and the resolution was $1024 \times 768$ pixels. Single pixels subtended $0.053^{\circ}$ visual angle (i.e., 3.18 arc minutes) as viewed from $27 \mathrm{~cm}$. For the eyetracking portion of the study, eye position was monitored using a monocular infrared tracking system (Videox Eye-Tracker Toolbox; Cambridge Research Systems) that samples eye positions every $20 \mathrm{~ms}$ with a resolution of $0.1^{\circ}$ and a tracking accuracy of 0.25 to $0.5^{\circ}$.

\section{Participants}

Thirteen observers with strabismus, one with anisometropia and one with form-deprivation amblyopia, participated in the mapping experiment.

Details of the amblyopic observers can be found in Table 1. Stereo acuity was measured with the Randot test (Stereo Optical Co. Inc., Chicago, IL), and the angle of squint was determined with an amblyoscope (Major; Clement Clarke, Harlow, UK). Five control observers took part in the mapping experiment. Refraction was undertaken, and any ametropia corrected to the best optotype acuity by using a logMAR chart in all observers. All studies were performed with the informed consent of participants, were approved by the Research Ethics board of the Montreal Neurologic Institute, and adhered to the tenets of the Declaration of Helsinki.

\section{Stimulus Construction}

The stimulus consisted of a 2-D Gaussian blob subtending $0.5^{\circ}$ visual angle (full width at half height) constructed with the following equation:

$$
g\left(x_{i}, y_{j}\right)=0.5+\left(0.5^{*} e^{-\left[\frac{\left(x_{i}-x_{\text {peak }}\right)^{2}}{\sigma_{x}^{2}}\right]} e^{\left.-\left[\frac{\left(y_{j}-y_{\text {peak }}\right)^{2}}{\sigma_{y}^{2}}\right]\right)}\right.
$$

where $x_{i}$ and $y_{j}$ represent the pixel location in an image matrix with dimensions corresponding to the desired visual angle, $x_{\text {peak }}$ and $y_{\text {peak }}$ represent the spatial coordinates of the center of the 2-D Gaussian function, $s_{x}$ and $s_{y}$ represent the SD of the 2-D Gaussian, and finally, $g\left(x_{i}, y_{j}\right)$ is the 2-D Gaussian function itself. The 2-D Gaussian function modulated between 0.5 (i.e., mean luminance) and 1.0 on a normalized $(0,1)$ pixel luminance scale; thus the luminance at the peak of the function was $80 \mathrm{~cd} / \mathrm{m}^{-2}$ (Fig. 1).

\section{Psychophysical Procedure}

Viewing was dichoptic, each participant wore a pair of polarized glasses so that each eye could be presented with separate stimuli (e.g., one eye was presented with a Gaussian blob, and the other was presented with a mean luminance display; Fig. 2A). By the use of a polarizing sheet in front of the monitor that could be switched at the frame rate (MacNaughton, Inc., Beaverton, OR), different stimuli could be presented to each eye on a frame-by-frame basis. Sessions were balanced such that each eye would be tested an equal number of times in random order. The general psychophysical task involved presenting each observer's stimulated eye (the affected eye for those with amblyopia and the nondominant eye in normal subjects) with a sharp-edge fixation dot placed at the center of the display for $500 \mathrm{~ms}$. This task was followed by the presentation of a Gaussian blob at one of 32 possible locations $(500 \mathrm{~ms})$, while the observers continued to fixate the circular fixation dot, which remained present during the presentation of the Gaussian blob (Fig. 2A). After the Gaussian blob was extinguished, the mouse cursor (previously hidden) was replaced with a Gaussian blob (always starting at the center of the display) visible only to the other eye (the fellow fixing eye of the amblyopic subjects and the dominant eye of normal subjects) at which time observers were required to move it (via the mouse) to the location at which they had just perceived the previously presented Gaussian blob and click one of the mouse buttons to indicate the response (Fig. 2B). The duration 


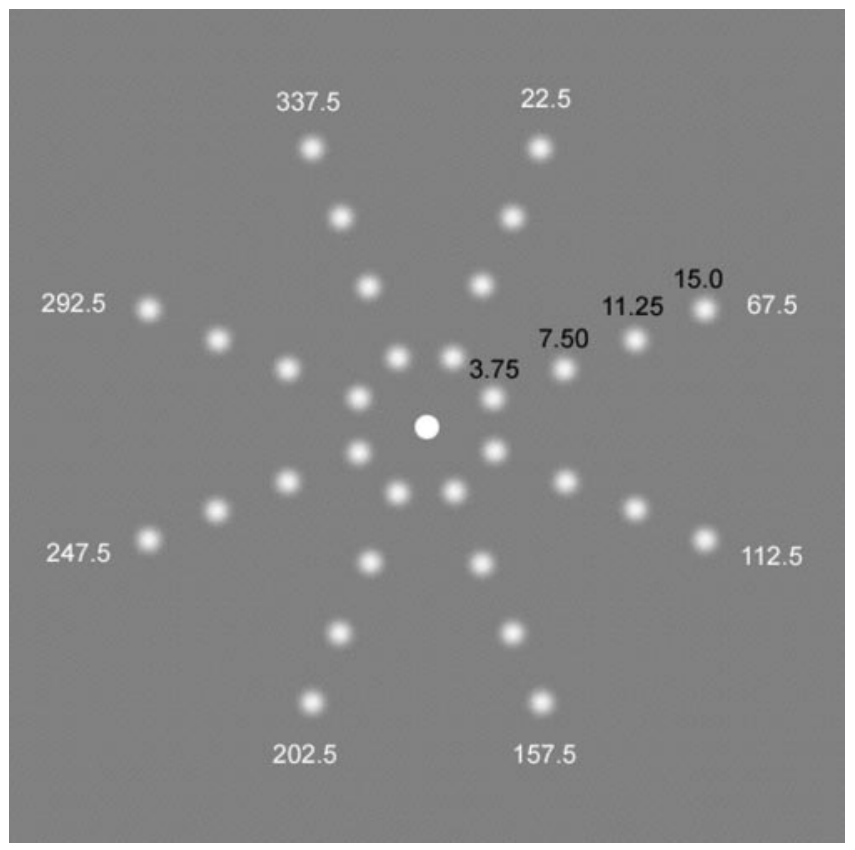

Figure 1. The 32 possible locations at which the Gaussian blob was presented. On any given trial, only one Gaussian blob was presented at one of the locations. At the center is the fixation point where observers were required to fixate during the presentation of the Gaussian blob. Black numbers: distance from the fixation in degrees of visual angle; white numbers: the location of the Gaussian blobs across $\theta$ in degrees (i.e., in polar coordinates)

of the response interval was unlimited. This procedure was repeated 64 times (twice for each of 32 locations of the Gaussian blob), and the entire session was repeated 10 times, with five of the sessions run for the amblyopic eye and five for the fellow fixing eye. The identical procedure was performed in the control observers on the dominant and nondominant eyes. An example of the 32 different locations at which the Gaussian blob could be presented is shown in Figure 1. The stimulation space was in polar coordinates, with distance from the center indicated in degrees of visual angle; four different eccentricities $\left(3.75^{\circ}, 7.50^{\circ}, 11.25^{\circ}\right.$, and $\left.15.0^{\circ}\right)$ were investigated (see Fig. 1 for further details).

\section{Analysis}

To quantify the degree of positional uncertainty and distortion in amblyopia we computed three measures termed, accuracy, resolution, and distortion. These quantities are measured at local regions in the field, and an index measure is computed for different regions of interest within the visual field as a whole.

Accuracy is quantified by the distance between the average of the matched locations and the true location, while resolution is quantified by the variability of the matched locations (i.e., SD). Distortion is quantified by the ratio of accuracy divided by resolution. Low values of the accuracy measure means good accuracy, and low values of the resolution measure means good resolution. In the plotted figure, red dots denote true locations where accuracy is worse than resolution, that is where the true location is outside the area defined by the average location and its $\mathrm{SD}$, in other words locations where distortion is significant (based on $1 \mathrm{SD}$ ).

A region of interest (ROI) analysis is performed by computing for each region an index of distortion based on the above criterion (accuracy measurement $>$ resolution measurement). The above criterion defines a binary entity at each location that is summed over the ROIs and divided by the number of locations that compose the ROIs. This results in an index between 0 and 1 that quantifies the level of distortion across the visual field. This index (called the distortion index) is independent of the ROI's size, and allows comparison of the distortion among different ROIs for a given subject. An index of 0 means that no location in the ROI under consideration shows a significant distortion. An index of 1 means that all locations in the ROI under consideration show a significant distortion.

The ROIs considered in the analysis are hemifields and quadrants and also defined along the radial and angular dimensions: top, bottom, left, and right hemifields and top-left, top-right, bottomright, bottom-left, center-top, center-left, center-bottom, and centerright quadrants.

A

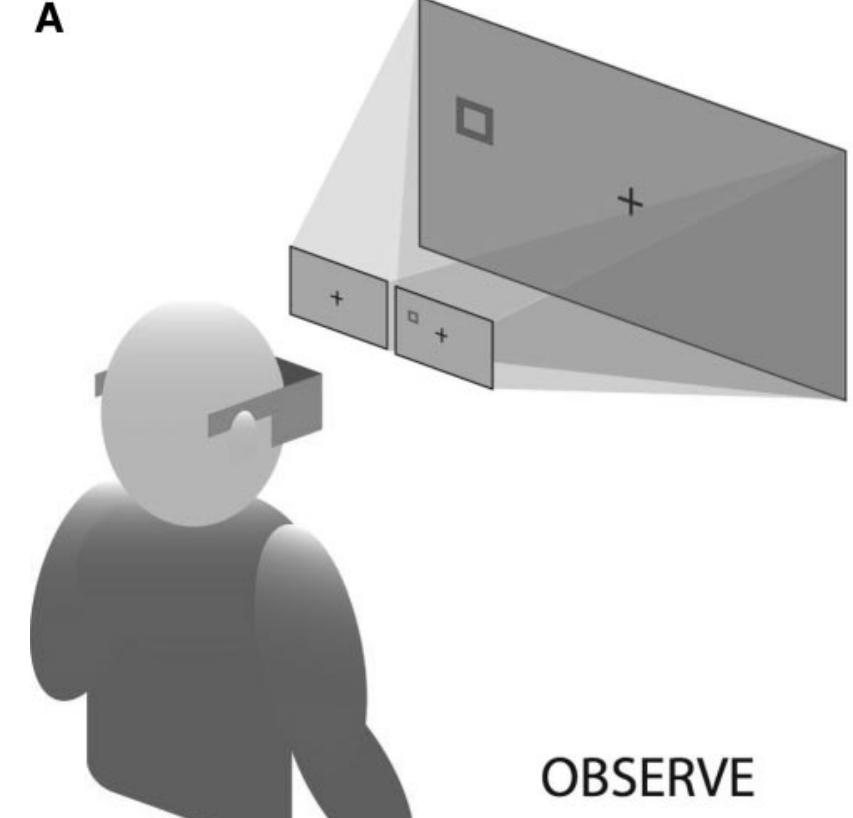

B

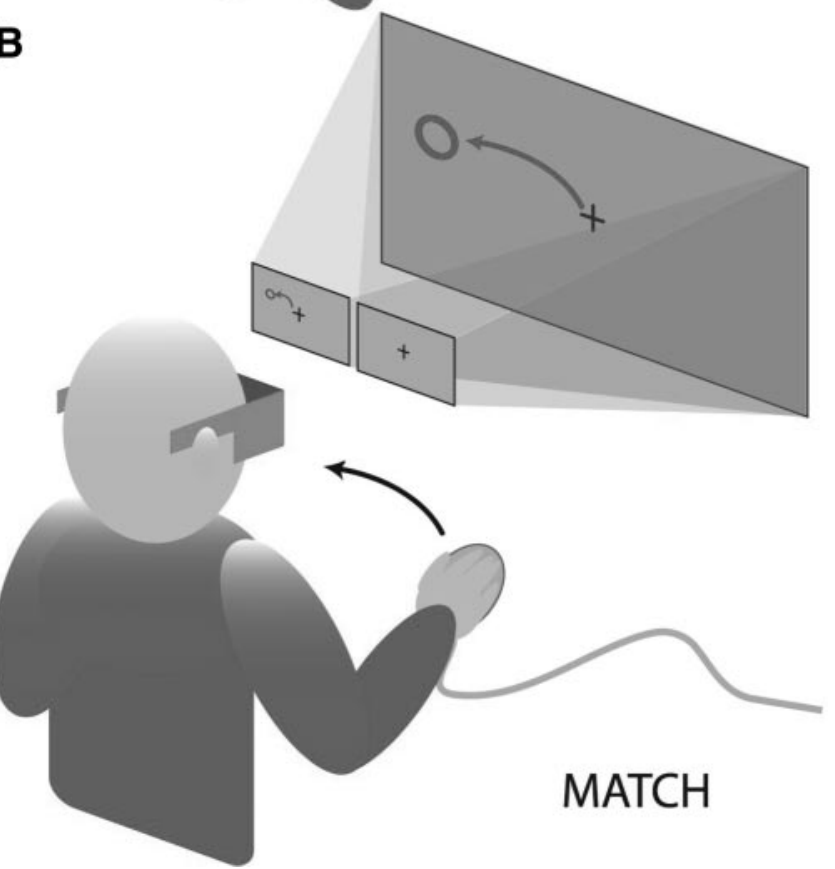

FIGURE 2. Viewing arrangement for the dichoptic presentation of test (A) and matching (B) stimuli (interocular matching). The fixation point, illustrated here as a plus, was actually a circle, as shown in Figure 1. 
FigURE 3. A sample-matching result using perceptual matching is presented for a normal subject $(\mathrm{BH})$. Black circles: the position where the blobs were presented to the dominant eye. Green circles: the actual matched positions by the nondominant eye. Red circles (not shown) indicated the locations where significant distortion was observed. Blue dots: $1 \mathrm{SD}$ around the average matched positions.

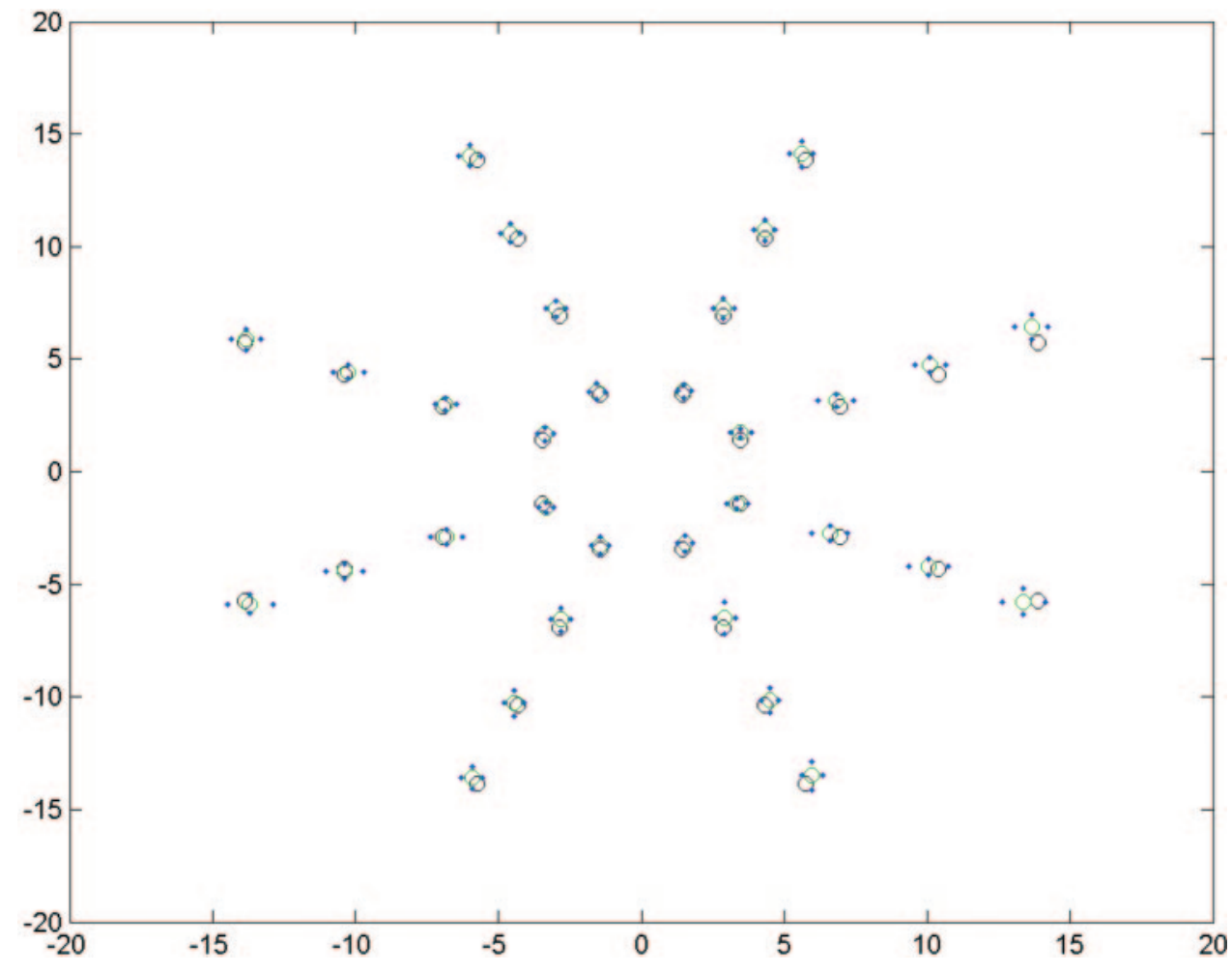

subject (Fig. 3). Stimuli were presented individually at several visual field locations to the amblyopic eye (while the fellow fixing eye viewed a mean luminance) and matched (interocular matching) by using a fixation dot seen only by the fellow fixing eye (while the amblyopic viewed a mean luminance). The test was performed similarly for the dominant and nondominant eyes of the normal observer. The grid positions on which individual stimuli were presented are marked in black. The

Figures 3 to 6 show sample results from three amblyopic subjects (two with strabismus and one mixed) and one normal

by the analysis (called resolution). This index is a quantitative measure of the resolution across the visual field. It is independent of ROI's size.

\section{Results}

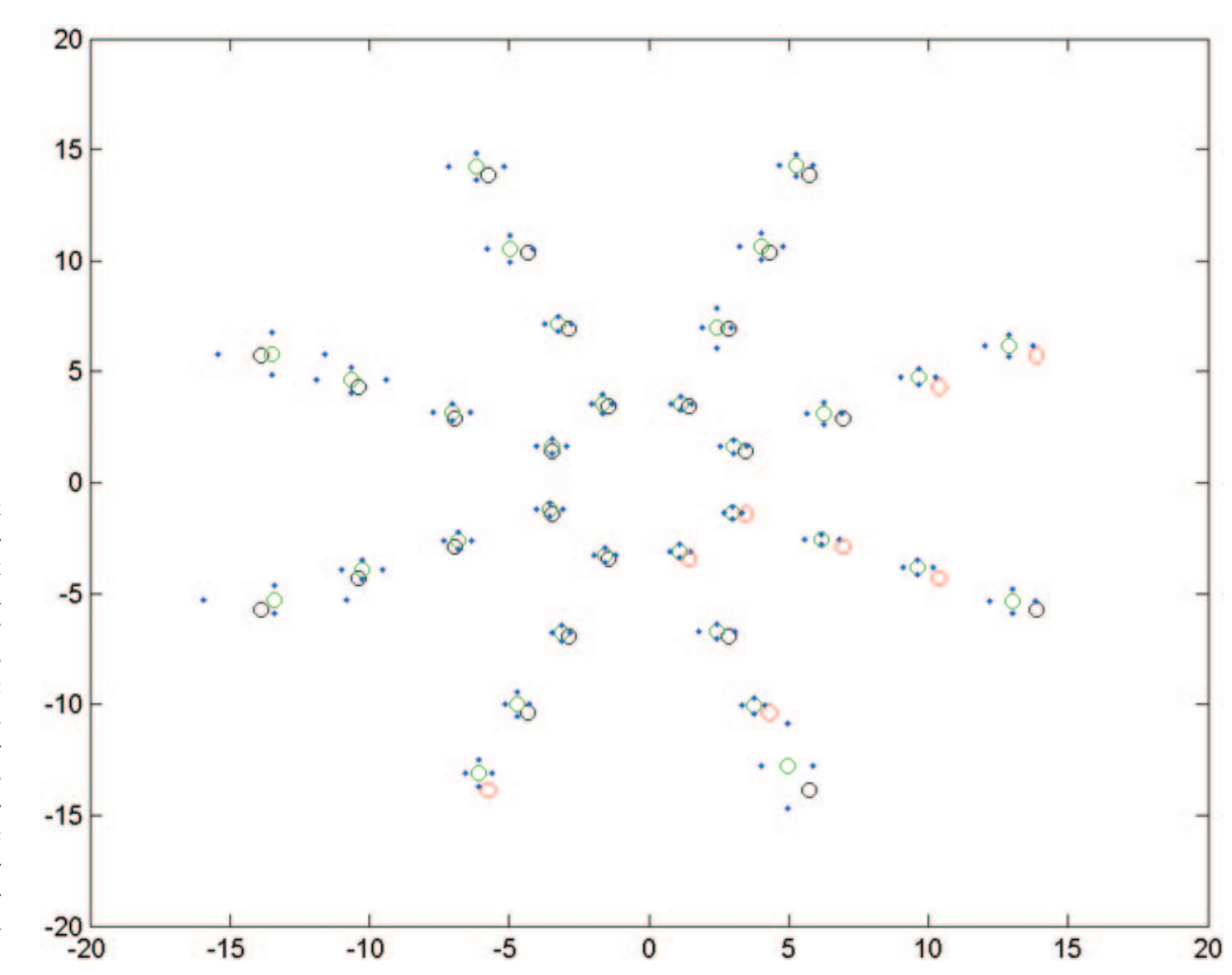

FIGURE 4. A sample-matching result using the perceptual matching is presented for one amblyopic subject (GN) who had anisometropia and a postsurgical 14-PD esotropia. Black circles: the position where the blobs were presented to the amblyopic eye. Green circles: the actual matched positions by the fellow fixing eye. Red circles: the locations where significant distortion was observed. In the areas where there are significant distortions, red circles replaced black circles, denoting stimulus position. Blue dots: $1 \mathrm{SD}$ around the average matched positions. 


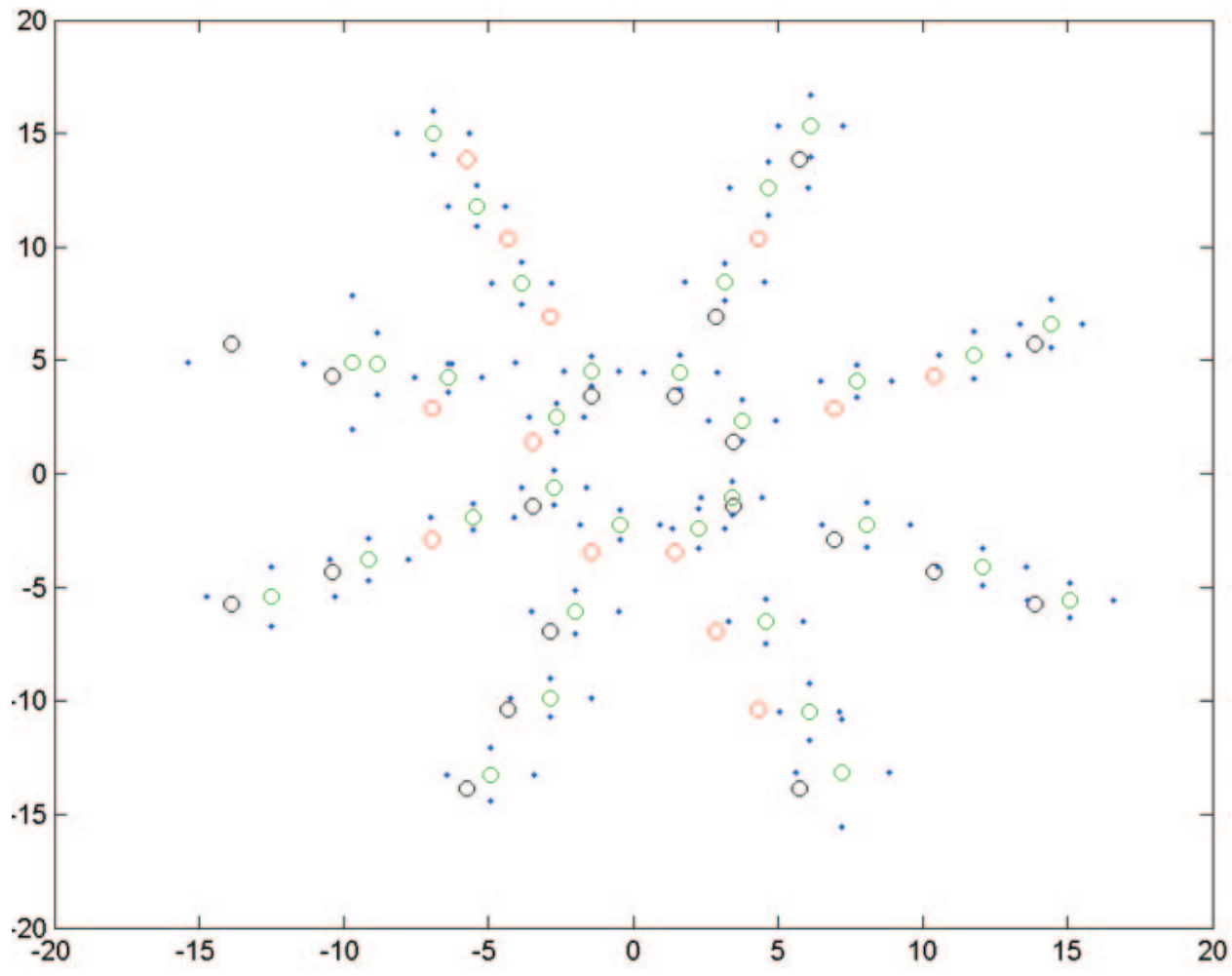

Figure 5. A sample-matching result using the perceptual matching is presented for one amblyopic subject (PH) who had a postsurgical 9-PD esotropia. Black circles: the position where the blobs were presented to the amblyopic eye. Green circles: actual matched positions by the fellow fixing eye. Red circles: locations where significant distortion was observed. Blue dots: $1 \mathrm{SD}$ around the average matched positions. In the areas where there were significant distortions, red circles replace black circles denoting stimulus position. green circles indicate the equivalent matches made by the fellow fixing eye (or dominant eye of normal subjects). The red circles indicate the locations where there were significant mismatches (i.e., the distortion measure). Where there are significant positional mismatches, the red circles replace the black circles in denoting the stimulus position. The blue dots represent one $\mathrm{SD}$ around the average matched positions (i.e., the resolution measure). It can be seen that these amblyopic eyes exhibited small but significant losses in accuracy and resolution. The distortion measure was computed from accuracy/resolution and is significant in some parts of the field. Losses in accuracy and resolution measures can occur in different regions within the central field of view and are not tightly correlated. For example, GN (Fig. 4) exhibited loss of

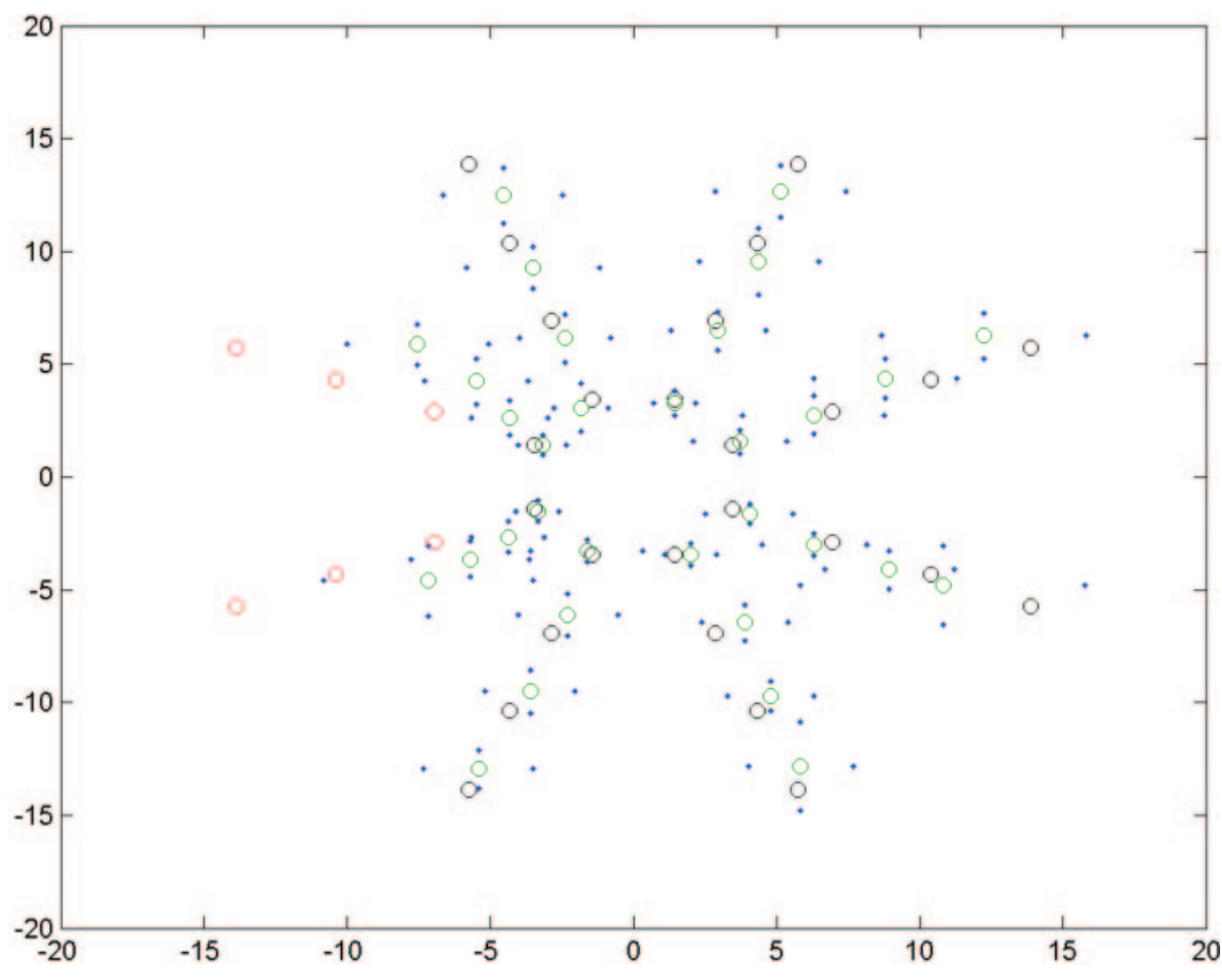

FIGURE 6. A sample-matching result using the perceptual matching is presented for one amblyopic subject (RA) who had 4-PD exotropia (no surgery). Black circles: the position where the blobs were presented to the amblyopic eye. Green circles: the actual matched positions by the fellow fixing eye. Red circles: locations where significant distortion was observed. Blue dots: represent one SD around the average matched positions. In the areas where there are significant distortions, red circles replace black circles denoting stimulus position. 


\section{(A)} Quadrantic ROI comparison of Amblyopic and
Normal eyes

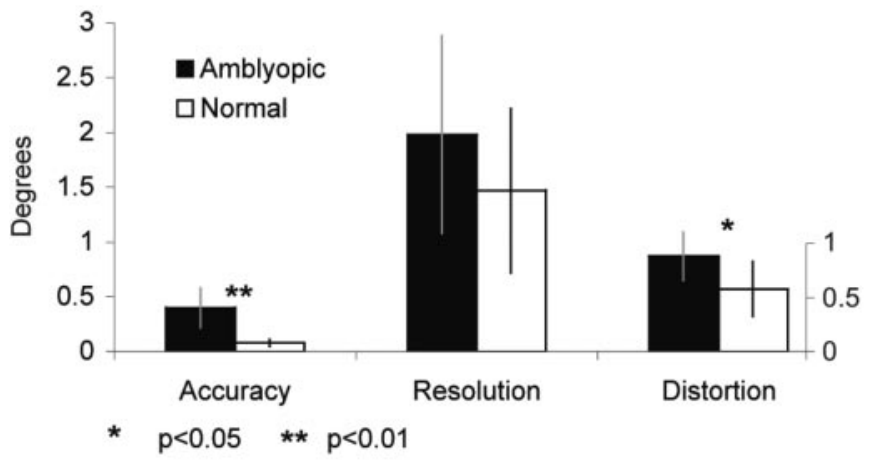

(C)

Polar ROI comparison of Amblyopic and Normal eyes

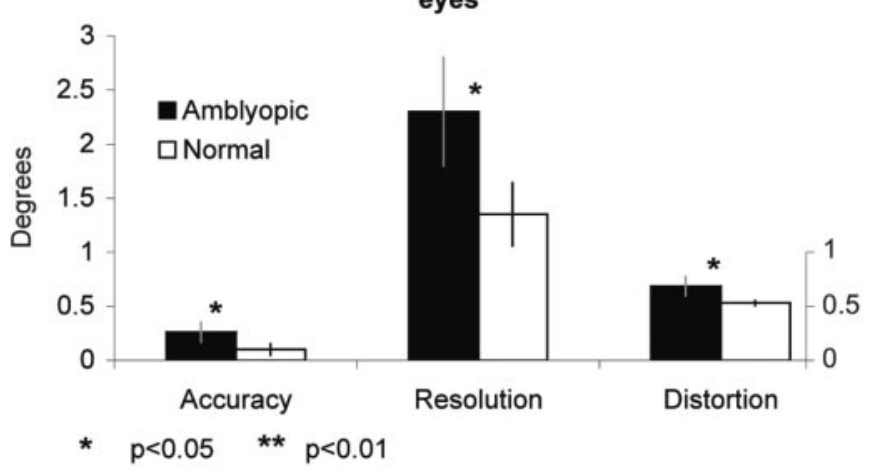

(B)
Radius ROI comparison of Amblyopic and Normal eyes

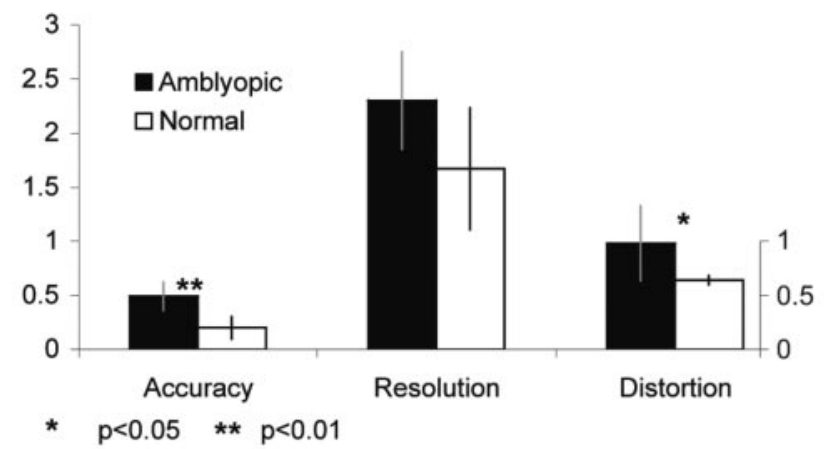

(D)

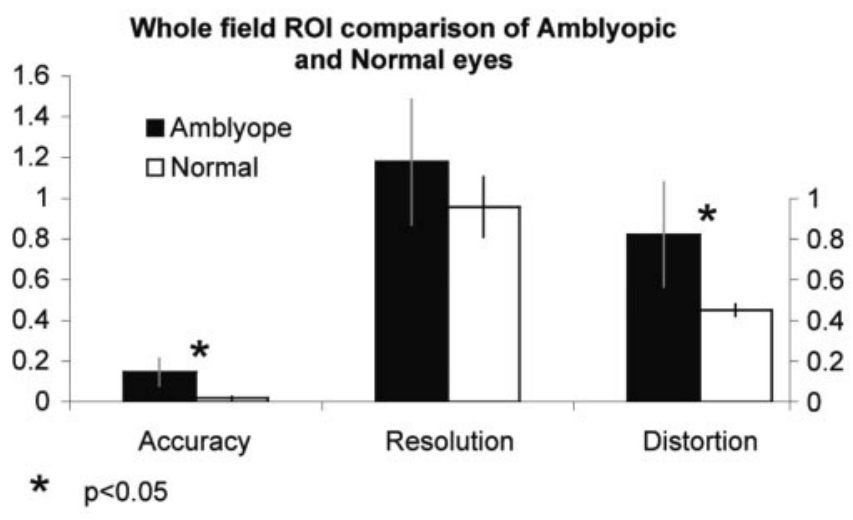

FIGURE 7. Accuracy, resolution, and distortion measures are compared in amblyopic ( $\square$ ) and normal observers ( $\square$ ) for (A) quadrantic, (B) radius, (C) polar, and (D) whole-field ROIs. Accuracy and resolution are measured in degrees, and distortion is a ratio.

accuracy without a loss of resolution whereas RA (Fig. 6) had resolution loss over much of the field only a part of which exhibited accuracy loss.

\section{Regional Nature of the Deficit}

We were surprised to find that the distortion was not evenly distributed across the central field of view, as was evident in the example results displayed in Figures 4 to 6 . We found regional losses in some subjects that involved quadrants of the visual field. For example, GN (Fig. 4) and RA (Fig. 6) exhibited distortion over only limited regions of the temporal field, whereas PH (Fig. 5) showed a more even distribution. Such a varied pattern of loss cannot be solely determined by the present angle of strabismus, since GN and $\mathrm{PH}$ had a similar sized esotropic deviation and yet had very different regional distributions of distortion, and GN and RA had similar regional distribution of distortion and yet very different strabismus (i.e., exo- versus esotropia). However, such a conclusion must be qualified by the fact that comparing results solely in terms of the strabismus potentially ignores other important differences in the orthoptic status among these subjects. Figure 7 shows an analysis of the computed index measures of accuracy, resolution, and distortion across the population of amblyopic and normal observers for different ROI analyses (e.g., quadrantic, radial, polar, and whole-field).

For all these different ROIs, the magnitude of each of our three derived measures (i.e., accuracy, resolution, and distortion) are raised in the amblyopic eye, because different amblyopic subjects displayed different regional distributions of posi- tional loss. The measure of distortion was significantly raised for all ROIs, suggesting that across a population of persons with amblyopia a variety of different regions can be affected. That the positional anomalies showed such regional variation, including circumscribed quadrantic deficits, makes it less likely that they developed as a direct consequence of the type of strabismus. However, our lack of information on the sensory and motor status of these patients during early visual development makes it difficult to come to a firm conclusion.

\section{Relationship between Accuracy, Resolution, and Acuity}

The results in Figures 4 to 6 suggest that subjects with amblyopia can have elevated positional variability (reflected in the resolution measure) in regions where the average position estimates are normal (the accuracy measure) and vice versa. Regardless of the regional distribution, do subjects with loss of accuracy also have loss of resolution and is this because of their poorer letter acuity?

The results in Figure 8A show the accuracy measure derived for each subject (within the appropriate ROI for each subject) with subjects arranged in ascending order of anomaly. Figures $8 \mathrm{~B}$ and $8 \mathrm{C}$ maintain the same subject order for the resolution (i.e., variability) and acuity measures, respectively. It is immediately obvious that there is no tight correlation between accuracy and resolution (i.e., variability) or between either of these measures and acuity. The correlations between each of these three measures is given in Table 2. More severe ambly- 


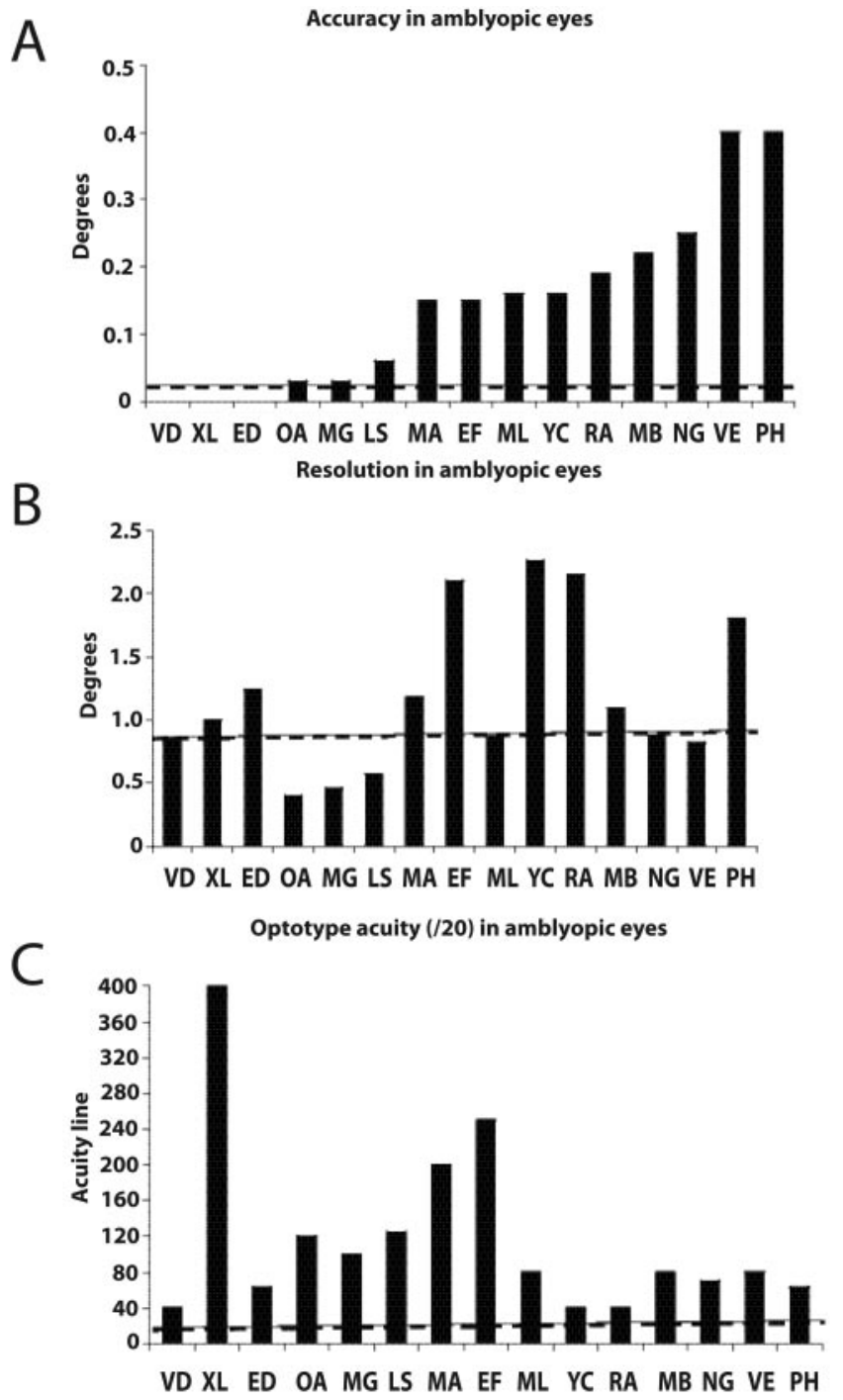

Figure 8. (A) Accuracy (i.e., average position estimate), (B) resolution (i.e., variability), and (C) optotype acuity are presented for 12 amblyopic observers. Dashed lines: normal average. Accuracy (A) correlated with neither the resolution (i.e., variability) nor the optotype acuity.

opia, as determined by acuity, does not necessarily cause more positional variability or more distortion. A similar lack of significant correlation for each of these parameters was obtained when we computed the correlations for just strabismic amblyopia (excluding deprivation and anisometropic amblyopia).

TABLE 2. Group Correlations and Associated Significance Levels for the Measures of Accuracy, Resolution, and Visual Acuity

\begin{tabular}{lccc}
\hline & Accuracy & Resolution & VA \\
\hline Accuracy & & & \\
$\quad$ Pearson correlation & 1.000 & 0.396 & -0.268 \\
$\quad$ Significance (two-tailed) & & 0.144 & 0.334 \\
$\quad \begin{array}{l}\text { Resolution } \\
\quad \text { Pearson correlation }\end{array}$ & 0.396 & 1.000 & 0.062 \\
$\quad$ Significance (two-tailed) & 0.144 & & 0.827 \\
VA & & & \\
$\quad$ Pearson correlation & -0.268 & 0.062 & 1.000 \\
$\quad$ Significance (two-tailed) & 0.334 & 0.827 & \\
\hline
\end{tabular}

In all groups, $n=15$.
A
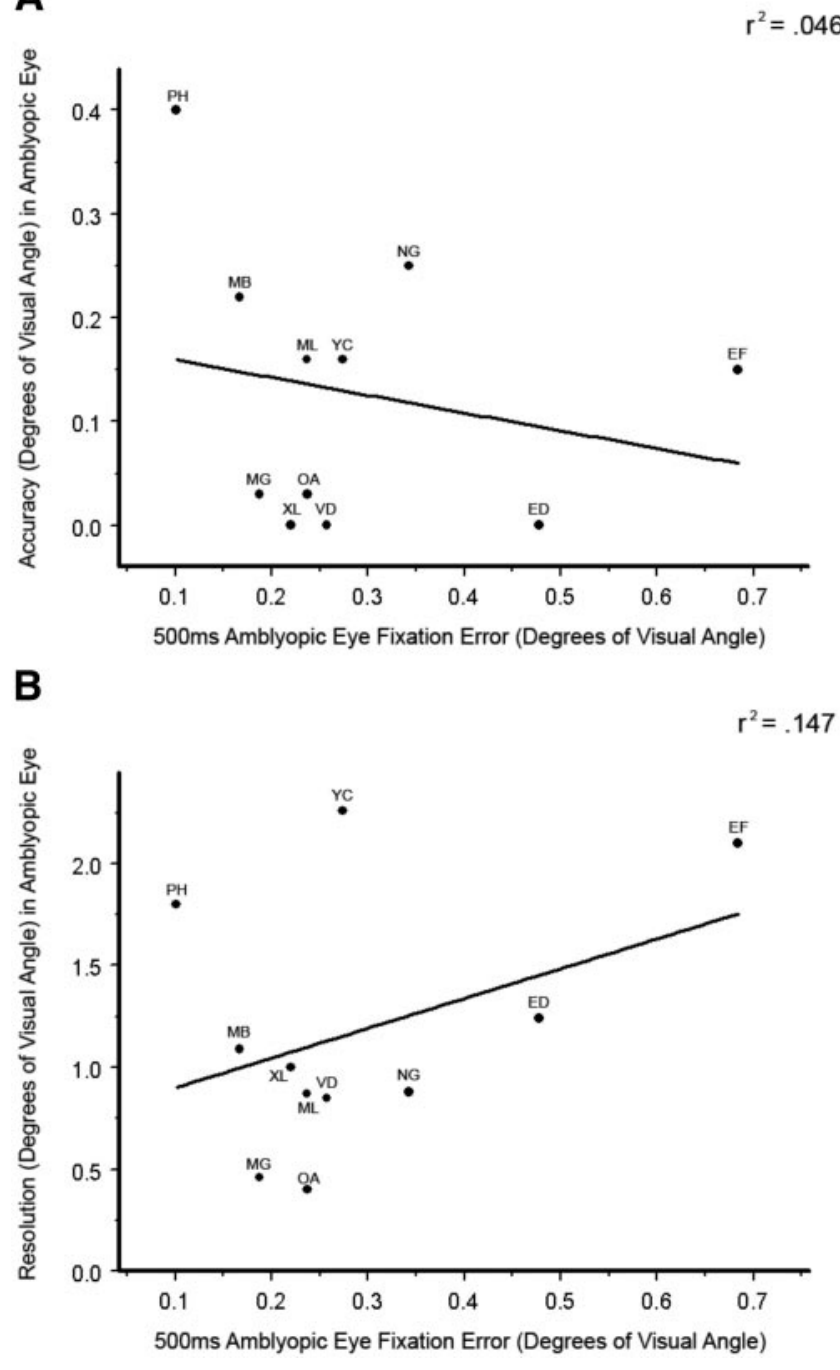

FIGURE 9. Relationship between measured oculomotor instability during fixation by the amblyopic eye and the key positional measures of accuracy (A) and resolution (B). Neither correlation is significant.

In the present study, local reference stimuli were not used, and so a possible reason for the lack of correlation between the deficits of variability and distortion may be oculomotor inaccuracy of the amblyopic eye during the 500-ms pretrial fixation period. In 11 of the 15 subjects, we monitored oculomotor accuracy during the first $500 \mathrm{~ms}$ of fixation. Specifically, occulomotor stability (i.e., fixation stability) was assessed by taking the SD of the observed fixation differences (in degrees of visual angle) from the center of the fixation dot over the 500-ms pretrial fixation period (i.e., an estimate of fixation error for which smaller estimates indicate higher fixation stability and vice versa). The relationship between fixation stability and either distortion (the accuracy measure) or positional variability (the resolution measure) is plotted in Figure 9. No significant correlation was found between either distortion $\left(r^{2}=0.046\right.$, accuracy measure) or positional variability $\left(r^{2}=0.147\right.$, resolution measure). The form of the results regarding resolution is suggestive of a relationship but it failed to reach significance.

\section{Discussion}

In this study, we sought to provide answers to two currently unresolved questions concerning the positional deficits in ambly- 
opia: Is there a relationship between the deficits for distortion, variability, and acuity? What is the regional distribution of these deficits? We did not find any relationship between variability (quantified by the resolution measure), distortion (quantified by the accuracy measure), and acuity (optotype acuity) in our group who are mainly subjects with strabismic amblyopia. Not only were the correlations low in any one part of the field, but also they often exhibited an entirely different regional distribution.

Previous measurements showing that the amblyopic eye exhibits increased positional variability have all involved the use of reference stimuli with which any effect of fixation instability would have had little or no influence on relative position judgment. ${ }^{4,26}$ This conclusion receives support by the finding in normal subjects that spatiotemporal instability does not affect positional uncertainty for such targets unless it differentially affects the reference and test stimuli. ${ }^{27}$ In the present study, local reference stimuli were not used, and so a possible reason for the lack of correlation between the deficits of variability and distortion may be the oculomotor inaccuracy of the amblyopic eye during the 500-ms pretrial fixation period. In 11 of the 15 subjects, we monitored oculomotor accuracy during the first $500 \mathrm{~ms}$ of fixation (Fig. 9) and did not find a significant correlation between the accuracy of fixation and either positional variability or distortion.

In terms of the regional distribution, we were surprised to find such a diversity of field deficits within the central $30^{\circ}$. The positional deficits are not evenly distributed across the central $30^{\circ}$ of the visual field in most patients with strabismic amblyopia. Such a finding means that these deficits are less likely to have occurred on the basis of anomalous retinal correspondence secondary to a fixed strabismus, as such a deficit would not only bear a definite relationship to the direction of the strabismus but also be evenly distributed over the central field. We have no explanation for why the positional deficits, in some cases, should be localized to quadrants of the visual field.

The nature of the neural disturbance responsible for the elevated positional variability and distortion in amblyopia is not well understood. The suggestion that it could be due to there being fewer cells (sometimes loosely termed, undersampling $)^{21}$ is a possible explanation for the increased positional inaccuracy, but it is less clear without a specific model how this could account for distortions. The other suggestion involves a disarray in cellular connections as the result of a lack of calibration during development. ${ }^{22}$ Such a distortion could account for both inaccuracy and distortion. To date, the only evidence to support this theory is the finding that the retinotopic map in several early visual areas is represented with less fidelity for the input from the amblyopic eye. ${ }^{28}$ To qualify for an adequate explanation, such a mapping deficit should show the same regional distribution as shown here for the psychophysics. Since this varies from subject to subject (Figs. 4-6) and from one field location to another (Fig. 7), such a comparison would need to be made not only on a subject-by-subject basis but also on a field location-by-field location basis.

\section{Acknowledgments}

The authors thank Craig Aaen-Stockdale for drafting Figure 2.

\section{References}

1. Levi M, Harwerth RS. Spatio-temporal interactions in anisometropic and strabismic amblyopia. Invest Ophthalmol Vis Sci. 1977; 16:90-95.

2. Hess RF, Howell ER. The threshold contrast sensitivity function in strabismic amblyopia: evidence for a two type classification. $V i$ sion Res. 1977;17:1049-1055.
3. Levi DM, Klein S. Hyperacuity and amblyopia. Nature. 1982;298: $268-270$.

4. Bedell HD, Flom MC. Monocular spatial distortion in strabismic amblyopia. Invest Ophthalmol Vis Sci. 1981;20:263-268.

5. Hess RF, Holliday IE. The spatial localization deficit in amblyopia. Vision Res. 1992;32:1319-1339.

6. Hess RF, Field DJ, Watt RJ. The puzzle of amblyopia. In: Blakemore $\mathrm{C}$, ed. Vision Coding and Efficiency. Cambridge, UK: Cambridge University Press; 1990:267-280.

7. Bedell HE, Flom MC. Normal and abnormal space perception. Am J Optom Physiol Opt. 1983;60:426 - 435.

8. Bedell HE, Flom MC, Barbeito R. Spatial aberrations and acuity in strabismus and amblyopia. Invest Ophthalmol Vis Sci. 1985;26: 909-916.

9. Fronius M, Sireteanu R. Monocular geometry is selectively distorted in the central visual field of strabismic amblyopes. Invest Ophthalmol Vis Sci. 1989;30:2034-2044.

10. Fronius M, Sireteanu R. Localization disorders in squint amblyopia: horizontal line bisection and relative vertical localization (in German). Klinische Monatsblatter fur Augenbeilkunde. 1992;201: 22-29.

11. Fronius M, Sireteanu R. Pointing errors in strabismics: complex patterns of distorted visuomotor coordination. Vision Res. 1994; 34:689-707.

12. Lagreze WD, Sireteanu R. Two-dimensional spatial distortions in human strabismic amblyopia. Vision Res. 1991;31:1271-1288.

13. Lagreze WD, Sireteanu R. Errors of monocular localization in strabismic amblyopia. two-dimensional distortion (in German). Klinische Monatsblatter fur Augenbeilkunde 1992; 201:92-96.

14. Sireteanu R, Fronius M. Different patterns of retinal correspondence in the central and peripheral visual field of strabismics. Invest Ophthalmol Vis Sci. 1989;30:2023-2033.

15. Sireteanu R, Lagreze WD, Constantinescu DH. Distortions in twodimensional visual space perception in strabismic observers. $V i$ sion Res. 1993;33:677-690.

16. Demanins R, Hess RF. Positional loss in strabismic amblyopia: interrelationship of alignment threshold, bias, spatial scale and eccentricity. Vision Res. 1996;36:2771-2794.

17. Fronius M, Sireteanu R, Zubcov A. Deficits of spatial localization in children with strabismic amblyopia. Graefes Arch Clin Exp Ophthalmol. 2004;242:827-839.

18. Hess RF, Campbell FW, Greenhalgh T. On the nature of the neural abnormality in human amblyopia; neural aberrations and neural sensitivity loss. Pflugers Arch. 1978;377:201-207.

19. Mitchell DE. Recovery from early monocular visual deprivation in kittens. In: Yonas A, ed. Perceptual Development in Infancy: The Minnesota Symposia on Child Psychology. Mahwah, NJ: Lawrence Erlbaum Associates; 1988:1-34.

20. Gingras G, Mitchell DE, Hess RF. The spatial localization deficit in visually deprived kittens. Vision Res. 2005;45:975-989.

21. Levi DM, Klein SA. Sampling in spatial vision. Nature. 1986;320: $360-362$

22. Hess RF, Field DJ. Is the spatial deficit in strabismic amblyopia due to loss of cells or an uncalibrated disarray of cells? Vision Res. 1994;34:3397-3406.

23. Beck J, Sutter A, Ivry R. Spatial frequency channels and perceptual grouping in texture segmentation. Comp Vision Graph Image Process. 1987;37:299-325.

24. Flom MC, Bedell HE. Identifying amblyopia using associated conditions, acuity, and nonacuity features. Am J Optom Physiol Opt. 1985;62:153-160.

25. Barbeito R, Bedell HE, Flom MC. Does impaired contrast sensitivity explain the spatial uncertainty of amblyopes? Invest Ophthalmol Vis Sci. 1988;29:323-326.

26. Levi DM, Klein SA. Spatial localization in normal and amblyopic vision. Vision Res. 1983;23:1005-1017.

27. Badcock DR, Wong TL. The sensitivity of separation discrimination to spatiotemporal jitter. Vision Res. 1990;30:1555-1560.

28. Li X, Dumoulin SO, Mansouri B, Hess RF. The fidelity of the cortical retinotopic map in human amblyopia. Eur J Neurosci. 2007;25: $1265-1277$. 